\title{
Correction to: Development and Utility of an ELISA Method for Sensitive and Specific Detection of IgE Antidrug Antibodies
}

\author{
Lynn L. Jiang, ${ }^{1}$ Puneet Khandelwal, ${ }^{1}$ Adam W. Clarke, ${ }^{2}$ Ray Bakhtiar, ${ }^{1}$ \\ Linglong Zou, ${ }^{3}$ and Zhandong Don Zhong ${ }^{1,4}$
}

\section{Correction to: The AAPS Journal}

https://doi.org/10.1208/s12248-020-0413-z

During the production process, the author order of Zhandong Don Zhong and Lynn L. Jiang were inadvertently misplaced. Lynn L. Jiang is the first author of this manuscript; Zhandong Don Zhong is the last author.

The online version of the original article can be found at https:// doi.org/10.1208/s12248-020-0413-Z

\footnotetext{
${ }^{1}$ Specialty Bioanalytics, Teva Pharmaceuticals Inc., West Chester, Pennsylvania 19380, USA.

${ }^{2}$ R\&D, Biologics, Lead Antibody Discovery, Teva Pharmaceuticals, Sydney, NSW, Australia.

${ }^{3}$ Biologics Assays \& Technology, Teva Pharmaceuticals Inc., West Chester, Pennsylvania 19380, USA.

${ }^{4}$ To whom correspondence should be addressed. (e-mail: don.zhong@tevapharm.com)
} 